\title{
JUNG Y LA SABIDURÍA ORIENTAL
}

\section{JUNG AND ORIENTAL PHILOSOPHY}

\author{
Diego SÁnChez MeCA*
}

UNED

Resumen: El desarrollo de este trabajo se centra en el estudio de la Segunda Parte del volumen II de las Obras Completas de Jung, que lleva por título "Acerca de la psicología de la religión occidental y de la religión oriental», publicado en su traducción castellana en 2008. En este volumen, se recogen seis interesantes estudios de Jung sobre algunos textos y tradiciones de la India y de China, que representan un ejemplo excepcional del encuentro de un occidental con las sabidurías de Oriente. En concreto, la lectura de textos orientales le ofrece a Jung el apoyo de tradiciones milenarias, de doctrinas muy sutiles y elaboradas, y de métodos privilegiados de toma de conciencia con los que miles y miles de individuos que han intentado, a lo largo de los siglos, alcanzar un cada vez mayor conocimiento de sí y estados de superación cada vez más altos de sus limitaciones materiales y ordinarias, en contraste con los diferentes métodos psicológicos, psicoanalíticos y espirituales que han sido propios de la tradición occidental.

Palabras clave: Religión oriental, budismo tántrico, sabiduría, meditación, mantra, no dualidad, experiencia mística.

Aвstract: The development of this work focuses on the study of the Second Part of Volume II of Jung's Complete Works, titled "About the Psychology of Western Religion and Eastern Religion", published in its Spanish translation in 2008. This volume gathers together six interesting studies by Jung on some texts and traditions of India and China,

\footnotetext{
* Catedrático de Filosofía Contemporánea en el Departamento de Filosofía, UNED. E-mail: dsanchez@fsof.uned.es
} 
which representing an exceptional example of the encounter of a Westerner withthe wisdom of the East. In particular, reading oriental texts offers Jung the support of millenarian traditions, of very subtle and elaborate doctrines, and of privileged methods of awareness. Thousands and thousands of individuals have tried, over the centuries, to use these methods to reach an ever greater knowledge of themselves and achieves states in which they increasingly surpass their material and ordinary limitations, in contrast to the different psychological, psychoanalytical and spiritual methods that have been typical of the Western tradition.

KeYwords: Eastern religion, Tantric Buddhism, Wisdom, Meditation, Mantra, Non-Duality, Mystical experience.

\section{Oriente y Occidente}

El tema de la relación oriente-occidente es tan amplio y tan difuso al mismo tiempo que podría haber, sin duda, mil formas de tratarlo y de desarrollarlo. El peligro, por tanto, es el de dispersarse en una serie de generalidades de las que puede resultar difícil extraer algún mensaje o alguna enseñanza concreta. Para evitar este peligro es por lo que me ciño a algunos textos de Jung publicados en el volumen II de las Obras Completas que lleva por título «Acerca de la psicología de la religión occidental y de la religión oriental», publicado en su traducción castellana en $2008^{1}$, y que pueden servir de hilo conductor. Los he elegido porque me han parecido un excelente testimonio del encuentro de un occidental con la cultura y las tradiciones filosóficas de Oriente. En este sentido, es de destacar que lo que, ante todo, detecta Jung, en el primer plano de estas culturas orientales asiáticas, es la presencia de una pulsión arquetípica espiritual que da vida al proceso de individuación. Porque tras todos los métodos de meditación y de iniciación, y tras todos los caminos de espiritualidad, lo que él ve es un impulso de toma de conciencia que obliga a reconocer la naturaleza suprabiológica de las cargas energéticas que dan forma al mundo, y que transforman un modo ignorante de percibirlo y de vivirlo en otro nuevo e iluminado. Y eso es lo que le confirma en su desacuerdo con el biologismo sexualista y exclusivista de Freud.

1 Cfr. Jung, C.G., Acerca de la Psicología de la religión occidental y de la religión oriental: Obras Completas II, Madrid, Trotta, 2008, Segunda parte. 
Las distintas técnicas de meditación oriental testimonian la realidad de una energía espiritual como fuente creadora y principio de orden en el inconsciente, y que muestra un dinamismo que va mucho más allá de las puras leyes biológicas corporales. Lo mismo sucede en lo que se refiere a la verificación de su hipótesis del inconsciente colectivo a partir de estas tradiciones espirituales, que curiosamente muestran un fondo común de símbolos, intuiciones y arquetipos reconocible en productos culturales y fenómenos psicológicos muy distantes en el espacio y en el tiempo.

\section{El Comentario psicológico al libro de la gran liberación, de 1939}

De los escritos que Jung dedica a la cultura y a la espiritualidad oriental, uno de los más interesantes es su Comentario psicológico al libro tibetano de la gran liberación, publicado en 1939. Este libro tibetano es un texto del budismo tántrico de hace aproximadamente 13 siglos, que describe diversos métodos para alcanzar la superación de la ignorancia y, por tanto, el estado de iluminación. La mayoría de los textos y tratados de la espiritualidad oriental consisten justamente en tratar de enseñar un camino, un método para llegar a la iluminación. Y en lo que se diferencian es en el tipo de procedimientos y de métodos, que pueden ser distintos en función de la doctrina de la que parten, o sea, en función de si se trata de un método vedántico, de un método tántrico, de un método mahayana o hinayana, de un método taoísta, de un método zen o de un método del sivaísmo no dualista de Cachemira.

Veamos lo que este texto aporta como confirmación o matización a la idea jungiana del proceso de individuación, y qué problemas se derivan de esa comparación para la comprensión que el hombre occidental tiene de sí mismo y de su realización como individuo y como persona. Se podría decir que, de manera prácticamente unitaria, el Oriente asiático entiende la meta del proceso de individuación -es decir, el conocimiento y la realización de sí mismo-, como la consecución final de un estado supremo de iluminación-liberación que se alcanza después de haber seguido un largo y dificilísimo camino o entrenamiento al respecto. Y en su esencia, en lo que consiste ese estado supremo de liberación- 
iluminación, no es otra cosa que en lograr reconstituir en uno mismo la unidad que originariamente existía entre el hombre y el cosmos.

La tradición Vedanta dice que la esencia del hombre es Atman y la del universo es Brahman. Ahora bien, en la medida en que el hombre no es sino parte misma del universo, en la medida en que procede de él y vive en él, Atman (el hombre) y Brahman (el universo), coinciden, son idénticos. De modo que lo divino y lo perfecto que puede haber en el universo como característica de su propia esencia, está también dentro del hombre, ya que lo humano forma parte real y metafísica de lo divino. No obstante, la inmensa mayoría de los hombres tenemos más bien muy poco, por no decir nada, de divino. Es decir, nuestro yo individual y empírico no equivale, sin más, al Atman-Braman. Nuestro yo empírico existe en el mundo fenoménico oscurecido por la ignorancia, ligado al peso de la ley del karma, y en realidad es como una especie de camisa de fuerza que aprisiona y envuelve -y casi asfixia- al yo verdadero, que es el que forma parte de lo absoluto. Entonces, de lo que se trata es de liberar a ese sí mismo absoluto de la camisa de fuerza del yo empírico, librarlo del ciclo de las reencarnaciones, para que el yo absoluto, el Atman, salga de su prisión y recomponga su unidad, es decir, su no-dualidad con el Universo.

En los textos de las Upanishads, el absoluto, o sea, el universo, el ser, como UNO-TODO significa esta identidad entre atman y brahman, que es lo mismo que decir la no dualidad (advaita) entre el sí mismo de los sujetos individuales y el ser del universo. Los chinos, que son menos metafísicos y más concretos que los hindúes, entienden esta unidad atman-braman de modo menos idealista y mucho más concreto. En los tratados de alquimia interior china, esa unidad no es vista sino como la íntima correspondencia que existe entre microcosmos y macrocosmos. De manera que el estado de liberación-iluminación se comprende metafóricamente como una especie de retorno, en ciertos aspectos, a la fase prenatal, a la vida del feto en unión con la madre, en el sentido de que en ese estado se da la imagen más perfecta de la completa y perfecta armonía entre las fuerzas yin y las fuerzas yang.

En el Comentario al libro tibetano de la gran liberación, Jung se fija y comenta la técnica que este libro propone -o sea, el método para alcanzar el estado de no dualidad- y que no es otra sino un determinado empleo muy sofisticado y elaborado de la recitación de mantras. Los mantras son sílabas sagradas, esotéricas, que no tienen ningún significado en el lenguaje común y ordinario, pero que pueden, sin embargo, permitir el acceso a los aspectos metafísicos del universo. 
Y ese es el caso privilegiado de la probablemente más famosa de estas sílabas mántricas, que es la sílaba $O M$. En el budismo tántrico tibetano, $O M$ representa la totalidad del universo, o, mejor dicho, la esencia mística de ese UNO-TODO, que es la no dualidad. $O M$, por lo tanto, es un sonido articulado, pero no es una palabra. O sea -y esto es muy importante- no sirve para designar, para nombrar el TODO-UNO, sino que simplemente es un sonido que alude a él, que indica o que simboliza esa no dualidad.

Una palabra, tal como la definen los profesores de lengua, es la unión de un significante (que es el sonido) y un significado (que es su contenido semántico, lo que significa), existiendo entre ambos un vínculo convencional por el que tal sonido designa o nombra tal cosa. El mantra, por el contrario, es sólo un significante que no nombra ningún significado, sino que sólo lo sugiere, lo recuerda, lo evoca. Aun así, para que el mantra pueda mostrar o sugerir o permitir el acceso a ese significado al que alude, hacen falta estas dos condiciones: La primera es que no basta con que simplemente cualquiera de nosotros diga $O M$ para que automáticamente, de forma inmediata y como por arte de magia, su sentido metafísico último se haga presente. Para que ese sentido metafísico y místico del mantra se muestre es preciso que $O M$ se pronuncie con una determinada forma de respiración, con un determinado modo de recitarla que únicamente se consigue tras una larguísima y complicadísima práctica de entrenamiento meditativo. O sea, para captar, intuir y realizar el poder del mantra, no basta simplemente con pronunciarlo, sino que hay que hacerlo vibrar físicamente dentro del propio cuerpo. O dicho esto de otra manera, hay que producir, con la participación de todo nuestro ser, cuerpo y mente, un canto que se manifieste como sonido absoluto. Y absoluto aquí quiere decir el hecho de que, al cantarse, el mantra $O M$ tiene que anular cualquier otra percepción que no sea la de su propio sonar. Mientras suena $O M$ todo lo demás debe quedar borrado, cancelado, omitido y olvidado. $\mathrm{O}$ en otras palabras, todo debe quedar transformado, transfigurado en ese único sonido que suena excluyente y exclusivamente como $O M$.

Por lo tanto -y esta es la segunda condición- el individuo que pronuncia el mantra $O M$ en la meditación no puede tener ya ni otras palabras ni otras sensaciones ni otros pensamientos. Si en el momento de recitar el mantra se logra que todo lo que existe quede condensado, fundido en el sonido $O M$, entonces ya no se distingue un sí mismo del individuo que canta frente a un mundo de cosas y de ideas como ser del universo pensado o contemplado en la meditación. El sí mismo del que medita se vuelve también sonido $O M$ desde el momento en el que todo el universo se resume, se condensa y se manifiesta como ese canto 
o ese sonido $O M$. Y así es como la identidad del individuo con el universo, la identidad de atman y brahman, la no dualidad o unidad de los contrarios, se hace real y presente cuando OM vibra como el sonido de la unidad que reune y que contiene dentro de sí la diferencia entre sujeto y objeto, entre yo y mundo.

Por tanto, y en conclusión, OM como mantra puede realizar esa coincidencia entre atman y brahman, yo y mundo aboliendo la dualidad porque su canto concreto, vibrante, concentrado durante la meditación, puede hacer real y presente de manera verdadera esa coincidencia metafísica entre el sí mismo (atman) y el ser del universo (braman). A la vista de esto -que es lo que plantea o describe $E l$ libro tibetano de la gran liberación-, Jung da su explicación al por qué y al cómo, en su opinión, un determinado modo de recitar OM puede lograr tal estado de no dualidad. Y lo que viene a decir es que eso se consigue porque esa forma de recitar el mantra OM logra vencer la antinomia o la paradoja que existe entre el silencio (que es el dominio de la unidad) y la palabra (que es la expresión de la dualidad). Esta observación de Jung me parece agudísima e importantísima, porque da, por así decirlo, en el clavo y en la entrańa de todo este asunto que estoy intentado explicarles.

Esa antinomia entre silencio y palabra de la que habla Jung es, por ejemplo, la que explica por qué sólo el hombre tiene lenguaje y los animales no. El animal vive siempre en un estado de no escisión, o sea, de unidad de su ser mismo con la naturaleza. No tiene las dualidades que tiene el hombre, en el plano de su pensamiento (dualidad entre palabra y cosa, entre concepto y ser) ni la que tiene en el plano de su comportamiento (dualidad entre ser y deber-ser). Por eso los animales no tienen lenguaje, sólo emiten sonidos que son como significantes, ni tienen tampoco moral (es decir, son inmorales o, más exactamente, amorales).

Pues bien, lo que Jung dice de forma tan inteligente es que, puesto que el hombre vive consustancialmente siempre en la dualidad del lenguaje hablado, para expresar su no dualidad originaria, su unidad o identidad metafísica con el Uno-Todo, tiene que recurrir al mantra, que es la paradoja de una palabra silenciosa, una palabra silenciosa. Una palabra silenciosa (silenciosa en el sentido de que no dice nada, de que no transmite ningún contenido distinto a su sonido mismo) pero que funciona -dice Jung-en el individuo que la recita y en su acto de meditación como un símbolo de transformación.

¿Qué es esto de un símbolo de transformación? Pues es, según Jung, el símbolo capaz de superar -o sea, de ir más allá- de la diferencia que el lenguaje 
introduce siempre, por sí mismo, entre significante (sonido presente) y significado (contenido semántico ausente). Lo característico de un símbolo de transformación como el mantra $\mathrm{OM}$ es realizar la unidad concreta de estas dos cosas. Lo característico del símbolo de transformación, es que eso a lo que alude (la no dualidad) -y que es una realidad ausente, desconocida y no alcanzada para el individuo ordinario-, se llega a manifestar en él produciéndole un determinado efecto de transformación y de metamorfosis. La sílaba OM no es sólo, por tanto, un símbolo como metáfora que evoca el UNO-TODO, sino que es, debidamente pronunciada y cantada, metamorfosis, transformación del individuo que la recita, en cuanto hace posible la realización de la unidad entre su yo y el universo.

Naturalmente, esta coincidencia se produce sólo de manera instantánea, o sea, sólo como un momento, como un instante en el que algo que antes no se producía, se produce para dejar enseguida otra vez de producirse, cuando el individuo vuelve a su estado de conciencia normal. $\mathrm{O}$ sea, que la experiencia de la coincidencia de atman y brahman, yo y mundo, no se inmoviliza en una especie de detención atemporal de ese estado como algo definitivamente ya alcanzado, sino que necesita, para continuarse, de la reactualización, de la reiteración una y otra vez de la experiencia de la unidad a través de la producción de símbolos siempre nuevos en la práctica diaria de la meditación.

\section{Psicología de la meditación oriental, de 1943}

Este otro texto de Jung es un comentario a un sutra del siglo $\mathrm{V}$, escrito en sánscrito, pero difundido sobre todo en China y Japón titulado Amitabayundhiana Sutra (Tratado de meditación de Amitaba). También, en este caso, este texto sánscrito contiene la descripción de otro método de meditación a través de visualizaciones por las que el meditante puede alcanzar el estado de iluminación.

En este segundo texto elegido, Psicología de la meditación oriental, Jung encuentra y comenta otro método igualmente sutilísimo e interesante descrito en el Tratado de meditación de Amitaba para alcanzar el mismo estado de iluminación o de realización de sí mismo, pero esta vez en vez del empleo de mantras, lo que se utilizan son visualizaciones como símbolos de transformación. Es decir, 
lo que contiene este Tratado de meditación de Amitaba es, sustancialmente, la descripción de un método de meditación que consiste en preparar al meditante para crear mentalmente una serie cada vez más compleja y cada vez más complicada de imágenes, e ir luego entrelazándolas hasta construir con todo detalle una figura de la perfección que pueda ser visualizada de la manera más nítida y real posible.

La figura o imagen de la perfección que este tratado propone es la de una flor de loto que ha de tener 84.000 pétalos, de los cuales cada pétalo tiene que tener 84.000 nervaturas de 84.000 radios cada nervatura. Esta es la visión que se debe construir mentalmente debiéndose ser capaz de visualizar con claridad y nitidez todos y cada uno de estos detalles. Lo que Jung comenta sobre este texto rebate, desde el principio, la primera idea que tal vez, a la vista de estos métodos, a nosotros los occidentales tiende enseguida a venirnos a la cabeza. Jung dice que no se trata, en esta técnica de meditación -como tampoco en la anterior con mantras-, de autoinducirse ninguna especie de estado de trance, o de autohipnosis o de alucinación paranormal de manera que a uno le parezca estar viendo o experimentando algo que en realidad no existe, sino que sólo es producto de su sugestión y de su estado de conciencia alterado. Y también dice Jung que no se trata tampoco de diseñar una especie de representación fantástica, superpuesta a nuestra realidad cotidiana y empírica, la cual jamás podría ofrecernos ninguna imagen real y concreta de lo que podemos pensar como absoluta perfección iluminada. Ni tampoco se trata, en tercer y último lugar, de teatralizar el acto de meditación y de simular, o sea, hacer como que se ve, se siente y se alcanza una especie de supraconciencia en la que residiría la lucidez extrema.

En los métodos de meditación descritos no se trata de nada de todo esto. Lo que plantea el Tratado de meditación Amitaba es la formación de una imagen de la perfección iluminada de tal manera que, llegándosela a ver, el meditante pueda, y sólo entonces, transformarse en un ser iluminado. ¿Cómo puede ser esto? Puede ser porque no se trata de una imagen que se crea para ponerla en la imaginación delante de uno y verla y mirarla y contemplarla desde la dualidad de la imagen que se ve y del sujeto que la mira, sino que se trata de un determinado modo de transformarse uno mismo en eso que ve. El sentido de este método de meditación por visualización consiste, por eso, en ir construyendo, poco a poco, junto con la imagen, una experiencia vivida de la perfección. Se da por supuesta la coincidencia a priori, y la identidad, entre la perfección iluminada misma y la conciencia del sujeto meditante. $Y$ de lo que se trata es de actualizar, de hacer presente y de realizar esa unidad y esa identidad. Porque es de dentro de su propia conciencia y de su sí mismo de donde el meditante va sacando, va extrayendo 
esa imagen de la perfección iluminada que construye. Es su propia conciencia la que va construyendo y combinando las imágenes que acaban componiendo una visión en cuya construcción el propio meditante se ha ido transformando, pasando así de la dualidad a la no-dualidad.

El estado de la dualidad es en el que, por un lado está el sujeto que ve, y por otro, frente a él, las imágenes que visualiza. En el estado de no dualidad, en cambio, son lo mismo la visión y el sujeto que ha ido construyendo desde dentro de sí mismo esa visión y se ha ido transformando al hilo de esa construcción de la imagen. En esto consistiría justamente el nuevo modo de lograr, en este caso, el estado de liberación del individuo iluminado en la conciencia de su no-dualidad.

\section{EI Prefacio al I Ching, de 1948.}

Por último, el tercer escrito elegido, el Prólogo al I Ching, el libro chino de los cambios, fue escrito cuando Richard Wilhelm, el sinólogo amigo de Jung, publicó la traducción de este texto en 1948. El I Ching es probablemente el libro más antiguo de la humanidad, y lo que contiene, sustancialmente, es un método de predicción o de adivinación del futuro mediante el uso combinado de trigramas y hexagramas, sin recurrir en ningún momento a los esquemas occidentales de explicar y prever el futuro en función de relaciones de causa y efecto.

Lo que a Jung le interesa de este método es la posibilidad que plantea de que una situación psicológica personal e individual, un estado de ánimo, un problema se puedan expresar a través de un acontecimiento material del mundo externo de un modo tan completo y perfecto que entre ambas cosas se pueda admitir la existencia de una correlación sincrónica razonable. Si esto fuera así, es decir, si el método de predicción del futuro del I Ching funcionara realmente, entonces eso supondría que tendríamos que admitir un paralelismo entre los acontecimientos físicos del universo y los estados o situaciones psíquicas de los sujetos. Tendríamos que admitir la existencia de una sincronicidad entre lo que acontece en el mundo y lo que acontece dentro de nuestra psique, de tal manera que podríamos obtener conocimiento de lo uno a partir de lo otro. 
Naturalmente esto sólo puede ser así si se reconoce como supuesto básico el principio fundamental de la mentalidad oriental asiática: la pertenencia esencial del hombre al universo, e incluso la identidad real entre ambos, que los chinos entienden mejor como la equivalencia entre microcosmos dentro del macrocosmos.

\section{5. ¿Conflicto o complementariedad?}

Una vez expuesto brevemente el contenido de los tres textos elegidos, tenemos que referirnos ahora al significado de lo que aportan dentro del debate en cuyo marco Jung los estudia, es decir, por relación a su idea del proceso de individuación como impulso de conocimiento y de realización de uno mismo. Jung advierte una y otra vez que lo primero que cualquier occidental tiende a decir ante este modo oriental de lograr la realización de uno mismo es que esa unidad entre yo y el mundo, esa no dualidad de la identidad iluminada, ni es posible ni es tampoco deseable.

Lo propio de la mentalidad occidental, lo que más profundamente le ha caracterizado y le caracteriza, es, por un lado su convicción de la imposibilidad, consustancial a lo humano, de superar tanto el dualismo cognoscitivo y lingüístico entre pensamiento y ser (o entre lenguaje y cosa), como el dualismo moral entre ser y deber-ser. Y por otro, y como consecuencia de esto, lo que nos caracteriza también es nuestra alta valoración y estima del yo personal, de la conciencia individual como el fundamento más elevado de todo lo positivo que el hombre tiene: de su razón, de su libertad, de sus valores e ideales morales, de su ciencia, etc.

El occidental acepta, pues, y hasta cierto punto valora como positivo, el hecho de que el individuo sea un ser diferente y separado como por un abismo insalvable de la totalidad del mundo. Porque esa es la razón de su impulso de conocimiento y de su voluntad moral, ya que nunca se llega de manera efectiva ni a un conocimiento definitivo de la verdad absoluta ni a una realización moral de la perfección absoluta. Siempre se está en camino de ello, y esto es lo que estimula y fundamenta a los hombres en el desarrollo de su libertad, de su autonomía, de su creatividad, de su conciencia, etc. Para un occidental, esa coincidencia o 
identidad del yo con el mundo de la que hablan las sabidurías orientales sólo puede ser, en el mejor de los casos, una metáfora, o sea, una visión, en efecto, pero como simple espectáculo que se puede mirar sin perder nunca ni en ningún momento la conciencia de que, como yo que mira esa visión, soy otro respecto a esa visión que veo.

Desde el momento en que el yo quedara anulado, sobrepasado, sumergido o perdido en la realidad de lo que se ve o se siente, eso el occidental sólo lo puede entender como ebriedad, como trance, como sugestión, o sea, en definitiva, como locura. $\mathrm{O}$ el yo sigue consciente y bien entero, sabiendo que lo que ve o lo que canta son cosas diferentes de él mismo y que él mismo no es eso, o en cuanto se crea ser verdaderamente eso que ve o que suena es que está loco. En resumidas cuentas, para un occidental no es posible ni deseable imaginar ningún estado espiritual consciente que no esté referido claramente a un sujeto, o sea, a un yo personal. En cuanto el yo queda anulado o sobrepasado, lo que tiene lugar entonces no es otra cosa que una caída en el inconsciente, y por tanto, en algún modo o tipo de locura.

Ese es el frente de la discusión en la que Jung se ve envuelto. Para el oriental está muy claro que sí es posible una conciencia y una mente sin yo, y que la conciencia puede llegar a ser capaz, mediante el empleo de métodos -que no tienen nada de inducción a la locura-, de trascender el estado del yo haciéndolo desaparecer para alcanzar un nivel de conciencia superior y más elevado. El occidental, en cambio, piensa que la conciencia es siempre conciencia de algo, y por lo tanto conciencia de una diferencia entre el sujeto y ese algo que el sujeto ve, siente, conoce, etc. El occidental no entiende eso de que es posible una conciencia pura como superación de la mera conciencia personal individual, sin que esto signifique, para él, otra cosa que un simple caer en lo inconsciente. No puede entender cómo eso puede ser el logro o la conquista del más alto conocimiento de sí y del estado más elevado de realización de lo que uno propiamente y metafísicamente es. Le es completamente ajena y extraña esa idea de una conciencia pura, tan familiar, sin embargo, al oriental. Una conciencia en la que ya no hay ningún yo como sujeto frente a un tú o frente a un ello como objetos, sino que lo que hay es simplemente un ES, un ser que se autoilumina y que es precisamente Pensamiento, Espíritu, Uno-Todo, Brahman-Atman, Tao, Kundalini, etc. etc. 


\section{La diferencia en el concepto de meditación}

Éste es el conflicto al que resulta muy difícil encontrar solución. Jung ni lo intenta, y se guarda muy cautamente de dar la razón a ninguna de las dos partes. Lo que sí hace Jung es dar algunas razones de por qué se produce este desacuerdo, y de cómo se podrían ver las cosas para que la contradicción resulte menos radical e insoluble.

1) La primera se refiere a la diferencia existente en el concepto mismo de meditación que tienen el oriental y el occidental,

2) Y la segunda es la diversa actitud que ambos tienen también en lo que se refiere al cuerpo.

Para un occidental, la verdad se desvela al pensamiento siempre y únicamente a través del lenguaje. En Occidente siempre se ha pensado en el lenguaje como el lugar propiamente dicho donde se contiene la verdad. Por ejemplo, cuando se creía que la verdad procedía de una revelación divina, ésta se situaba en las escrituras sagradas que adquirían así el estatuto de palabra de Dios. Cuando ya no se cree en eso, la verdad sigue situándose igualmente en el lenguaje como lenguaje de las ciencias, porque son las teorías científicas las que nos dicen la verdad acerca de las leyes del universo, etc. En todo caso, la verdad va siempre unida a una dualidad nunca superable entre hombre y Dios, entre yo y mundo, o entre lenguaje y realidad.

En Oriente, en cambio, la palabra, el discurso sobre la verdad, viene siempre después y como descripción de una verdad previa y sin palabras que tiene que experimentarse antes. O sea, que para poder ser dicha y explicada con palabras, la verdad tiene primero que ser vivida en una experiencia. De ahí que meditar, para un oriental, no es -como hemos visto- reflexionar ni discurrir con conceptos ni contemplar ideas. Las palabras, los conceptos y las ideas son, para él, algo distinto de las cosas y de la realidad. La palabra no es la cosa. La cosa sólo puede experimentarse como tal superando o yendo más allá del lenguaje que simplemente la dice.

De manera que el oriental no se deja convencer de que la verdad esté en el lenguaje ni en las teorías, que son puros entramados de conceptos y de 
términos abstractos. Él insiste en que la verdad tiene primero que ser vista, escuchada, o sea, física y espiritualmente sentida y aprehendida como imagen concreta y llena de significado. Esta es la razón de por qué en la meditación oriental los conceptos y las palabras son sustituidos por visiones, por sensaciones, por símbolos como verdades que se manifiestan a través de figuras y de imágenes. No se razona con conceptos esquemáticos y vacíos, puras abstracciones intelectuales sin contenido concreto, sino que se experimenta con símbolos y a través de símbolos.

En cuanto a la diversa actitud que ambas mentalidades, oriental y occidental, adoptan en relación con el cuerpo, aquí podemos ver una importante clave para entender muchas cosas problemáticas de todo lo que llevamos visto. Porque para el oriental es impensable una meditación en la que no esté absolutamente involucrada la totalidad del cuerpo. El pensamiento occidental prescinde completamente, y de un modo incluso premeditado y preconcebido, de cualquier implicación del cuerpo, de las sensaciones, de las imágenes y de los sentidos en el pensamiento. Se trata, por todos los medios, de que el pensamiento de la verdad esté única y exclusivamente en los conceptos abstractos y en las palabras del lenguaje. Y el cuerpo queda entonces premeditadamente reprimido, rechazado, apartado como lo otro, como lo impulsivo, como lo inconsciente que estorba y amenaza con obstaculizar e impedir continuamente el puro discurso de la razón.

Frente a esta concepción, lo que caracteriza a la meditación oriental es, como hemos visto, que en ella están siempre implicados y concernidos tanto el pensamiento como el cuerpo. Lo primero que tiene que hacer el que practica la meditación oriental es adoptar una determinada postura con el cuerpo (o sea, cruzar las piernas, enderezar la espalda, fijar la mirada en un sólo punto). Tiene que ser capaz además de acompasar su respiración de modo que alcance un ritmo determinado, tiene que dominar el arte de la visualización de imágenes, tiene que eliminar las distracciones y el parloteo mental incontrolado... En suma, tiene que alcanzar un estado del cuerpo-mente como no dualidad en el que una determinada experiencia global hace su aparición y únicamente la hace bajo esas condiciones. En esta participación del cuerpo como elemento activo en el conocimiento de la verdad todos los detalles son importantes. Por ejemplo, es importantísimo, sobre todo el acompasamiento de la respiración. ¿Por qué? Pues porque la esencia del individuo es prana, o sea, aire, energía vital, chi, y eso mismo es también el universo. De modo que al respirar, el individuo está llevando a cabo una acción cósmico-metafísica. Concentrándose en la respiración y en su ritmo, el individuo experimenta ya de este modo tan elemental su 
coparticipación esencial y su unidad última con el cosmos. Y eso, junto con las posturas corporales y el control mental crea las disposiciones psicológicas que hacen posible intuiciones trascendentes a la conciencia.

De manera que la verdad no es sólo asunto de la parte intelectual y racional pura del individuo, sino que afecta y concierne también de un modo igualmente importante a toda su realidad corporal. Implica tanto a la mente como al cuerpo. Y esto es lo que significa la idea oriental de que, para alcanzar el estado de no dualidad, el pensamiento tiene que salirse del lenguaje -que es el reino propiamente humano de la dualidad-y hacerse pensamiento del cuerpo-mente en su totalidad.

En conclusión, no hay por qué reducir la meditación oriental a una inmersión en lo inconsciente, y por tanto, a una caída en la locura, sino que hay que entenderla como atribución al cuerpo de un papel esencial en la realización del pensamiento. Eso, y no cualquier otra cosa extraña, es lo que hay tras la devaluación oriental del lenguaje abstracto y de la conciencia puramente intelectual. Para Oriente, el inconsciente es ese Uno-Todo, esa totalidad de lo que existe o Tao en el que se funde y se une todo lo diverso. De ahí que pueda reaparecer en nosotros, dentro de nosotros, aunque sea también algo exterior a nosotros y que nos sobrepasa. 


\section{Bibliografía}

Azız, R. (1990). C. G. Jung's Psychology of Religion. New York: State University of New York Press.

Done, C. B. (2016). Jung's Wandering Archetype: Race and Religion in Analytical Psychology. London: Routledge.

Griffin, D.R. (ed.) (1989). Archetypal process: Self and divine in Witehead, Jung and Hillman. Evanston: Northwestern Univ. Press.

Hanegraaff, W. J. (2008). New Age Religion and Western Culture: Esotericism in the Mirror of Secular Thought. Leiden: E.J. Brill.

Huskinson, L. (2008). Nietzsche and Jung: The Whole Self in the Union of Opposites. London: Routledge.

Jung, C.G. (1999-2016). Obras completas, 18 vols. Madrid: Trotta.

Noll, R. (1997). The Aryan Christ: The Secret Life of Carl Jung. London: Random House.

O’Connor, P. A. (1985). Understanding Jung, understanding Yourself. New York: Paulist Press.

Stevens, A. (21999). On Jung. Princeton: Princeton University Press.

Trevi, M. (1987). Per un junghismo critic. Milán: Bompiani.

Wallace Clift, W. (1982). Jung and Christianity. New York: The Crossroad Publishing Company.

WeHr, G. (1991). Carl Gustav Jung: su vida, su obra, su influencia. Barcelona: Paidós.

Whitmont, E. C. (1979). The Symbolic Quest: Basic Concepts of Analytical Psychology. Princeton: Princeton University Press. 
WiLson, C. (1986). Il signore del profondo: Jung e il ventesimo secolo. Roma: Atanor.

Wulff, D. M. (1991). Psychology of Religion: Classic and Contemporary Views. New York: John Wiley \& Sons.

Recibido: 11/01/2018

Aceptado: 30/10/2018

Este trabajo se encuentra bajo una licencia de Creative Commons Reconocimiento-NoComercial-SinObraDerivada 4.0 